\title{
An Anxious Alliance
}

\author{
Kaiton Williams \\ Information Science \\ Cornell University \\ kaiton@cs.cornell.edu
}

\begin{abstract}
This essay presents a multi-year autoethnographic perspective on the use of personal fitness and self-tracking technologies to lose weight. In doing so, it examines the rich and contradictory relationships with ourselves and our world that are generated around these systems, and argues that the efforts to gain control and understanding of one's self through them need not be read as a capitulation to rationalizing forces, or the embrace of utopian ideals, but as an ongoing negotiation of the boundaries and meanings of self within an anxious alliance of knowledge, bodies, devices, and data. I discuss how my widening inquiry into these tools and practices took me from a solitary practice and into a community of fellow travellers, and from the pursuit of a single body goal into a continually renewing project of personal possibility.
\end{abstract}

\section{Author Keywords}

self-tracking; autoethnography; experience; quantified-self

\section{ACM Classification Keywords}

H.5.m. Information Interfaces and Presentation (e.g. HCI): Miscellaneous

\section{INTRODUCTION}

At the beginning of 2012 I decided that it was time to lose some weight, and I turned to a set of digital health \& fitness tools to help me on my way. I managed to lose the weight, but my journey with these systems continued and I substantially changed my patterns and everyday experiences in ways that ranged from the pedestrian to the sublime. Although this project was not initially intended as research but as part of an effort to address a real personal need, I believe that the journey has provided me with a new professional perspective on systems like these, and has taken me from a solitary practice into a community of fellow travellers, and from the pursuit of a specific body goal to a continually renewing project of personal possibility.

I embraced a personal, existential, crisis as an opportunity to try solutions that I had been critical of professionally or avoided personally. I considered this as an opportunity to develop an experiential understanding that was tied to a real personal need. Surely, I told myself at the outset of this project,

Copyright 2015 is held by the author(s). Publication rights licensed to Aarhus University and ACM.

5th Decennial Aarhus Conference on Critical Alternatives August 17 21, 2015, Aarhus Denmark

DOI: http://dx.doi.org/10.7146/aahcc.v1i1.21146 this would be better than critical analysis lobbed in from the outside.

The route would prove uncertain. I wanted to be in better control of my self and I wanted to understand how it felt to be healthy and fit. Yet, as I began to make progress towards my goals, I wondered about the changes in mind and body that were accompanying my technologically guided, deliberate movement. Was the quest for more information about myself and my immediate world helping me find either? And how might any acquired tracking tools, and the ability to navigate them, fit into my understanding of what it meant to be a modern connected person? Furthermore, where did the approach I was using - experiments and experiences within one's selffit within the toolkit of methods in use within HCI?

My retelling of that experience is presented here as a personal essay, building on Bardzell's articulation of the value of the essay form for a CHI audience [2], and inspired by Taylor's essay on the politics of research into cultural others in HCI [30]. My hope is that placing my self directly in the frame of analysis will highlight a tangle of personal and professional interests that are I believe should be embraced as we interact with, design, and sustain a discourse on systems that are ever more integrated into our everyday lives. These frames in which we pursue our health and fitness are neither fixed nor external but are created by, and depend on, our perceptions and beliefs, social norms, and our collective sense of technological possibility.

These unavoidably intimate concerns lend an approach centred on the self-as-site, self-as-subject a ready allure. The autoethnographic approach used here (and to various degrees previously in $[14,8,18]$ ), with its synthesis of postmodern ethnography and autobiography, is intended to call into question the objective observer position, the realist conventions of standard ethnography, and to disturb notions of the coherent, individual self and its binaries of self/society and objective/subjective [26]. In doing so, it has the potential to provide a conduit to what McCarthy and Wright refer to as the "rich interior world of felt life" necessary for producing empathetic understanding [36]. But while undoubtedly productive, the approach presented significant challenges-which manifest here-both in the shaping of a research agenda through the course of a personal transformation, and in the reporting of those results.

My primary goal is to generate an empathetic engagement with my experience, and through it, a connection with what 
could be the concerns and life paths of others in similar situations. But I intend my account of my experience to be an illustration, not general evidence or directly comparable to that of others. This is a distinctly idiosyncratic account, but it is through the production of idiosyncratic accounts that I believe we can find the empathy-as a view of our lives as entangled with others-that makes for a rich understanding of the role of personal devices in our lives. This requires highlighting, not suppressing, the vulnerability, motivations, personality traits, contradictions and stumbles that made up both my everyday experience and my attempts at analysing it.

This is then an attempt to perform a balancing act of personal revelation within the tent of scholarly discourse. And just how big that tent should be is also a matter that this essay takes into consideration. My contention is that, to faithfully convey that messy, polyvocal world that finds its berth in personal experience, the tent's boundaries need to be reshaped.

In reflecting on the essay's denigrated place in the $\mathrm{CHI} / \mathrm{HCI}$ canon, Bardzell suggests that the essay is the best form for doing just this work: for revealing "a process of thinking" that is still "shaped and crafted as a work of writing"[2]. He argues that the essay is positioned as only opinion within CHI, but he places it as part of a millennia-long tradition of trying to deliver exactly the kind of analytic understanding of experience that the field solicits. And that interpretative efficacy is delivered through the playing up of a sense-making subject apprehending "an object of study...[that] must therefore, be...in some sense confused, completely, cloudy, contradictory." This is necessarily the state of affairs in situations like these, where the subject and subjectivity are the sources of data.

This is more than an secondary note about construction. The essay's production is embedded in the transforming frame of the journey it describes and reflects that. The shifts in tense and tone that follow reflect concerns that transform, in stages, from a matter of physicality, to one of self-understanding, and into an ontological project of expanding possibility pursued in alliance with others.

At the same I remain faithful to an exploration of the pedestrian, and what Georges Perec referred to as the "infraordinary" or "endotic:" the small, quotidian, experiences that accumulate and become our lives. Perec charged his readers to join him and together "found our own anthropology, one that that will speak about us, will look in ourselves for what for so long we've been pillaging from others" [24]. He contrasted this exploration of small matters of concern against the big stories, the front page headlines and the spectacular. His exploration was to be one of the seemingly obvious and habitual:

It matters little to me that these questions [of the everyday] should be fragmentary, barely indicative of a method, at most of a project. It matters a lot to me that they should seem trivial and futile: that's exactly what makes them just as essential, if not more so, as all the other questions by which we've tried in vain to lay hold on our truth.

This is not to say that matters of concern of a larger scale are not important. It is vital that we understand the hybrid and structural phenomena around health and big data that knit together nations, social classes, forms of knowledge and inquiry with Latourian [16] hitches. In fact if others were not so ably investigating these matters, I would have no room to write an essay about the everyday and unspectacular.

\section{BEGINNING}

Just more than 1,377,584 measured calories ago I embraced a simple goal: to lose weight. This is one made, I'm certain, by millions of others every day. Yet, more than any highminded investigation into technologies, or into a community and its practices, it was this that drove my interest and kept me going.

I made the decision after the Christmas holidays, when my sister had come to visit. I prepared a feast and we dined sumptuously for several days. At the end of the visit, we went to the Pacific shore and took a few photos on instant film. It was then, as I watched those photos develop, that I realised how bad things had gotten. I had been slowly but steadily gaining weight even though I thought I was in control of my diet and getting enough exercise. I looked, in my own estimation, terrible.

Granted, as physical issues go, this was a minor calamity. Still, I decided then that I needed to not only get back in shape, but to find a place of steady balance. To be completely honest, I cannot say "back." I was only ever in shape for brief moments. I had only passed, momentarily, through shape. I wanted to remain there; wherever there was.

So as much as I loathed New Year's resolutions, I decided to get going a few days later. The immediate problem was that I didn't know how exactly to go about it. I knew the accepted wisdom was that I should eat less and exercise more but I didn't really know what I should eat less of, or what exercises I should perform.

I had done some research on health and fitness research previously and knew that a range of consumer tools existed. I knew about BMI, and even though I knew that number had contingencies, I knew that mine was too high. I knew what calories were but I didn't know how many I should be consuming. I more or less still ate according to ratios and formulae mimicked from my childhood.

But life was different in the here and now. I was surrounded by a stunning variety of foods, eating styles, and advertising schemes. A steady compass was hard to come by. I knew enough to avoid an all-cake diet, but where would I find salvation? Low-fat? Low-carb? I didn't know which to follow, or how to keep in line.

And what could I reasonably achieve? I had some vague goals from a variety of sources but I wasn't sure what good targets and limits should be. And I definitely had little formal idea of how to manage my consumption to meet them. 
There was an overwhelming amount of information to consume, much of it contradictory. In contrast, many of the applications I surveyed offered simple solutions. Download, launch, follow the prompts, and hit the suggested numbers. This was immensely attractive, even with my professional skepticism.

This remains something that I consider with a fair amount of irony. I was among a group of researchers who had been critical of this persuasive and reductive logic that powered many of the popular diet control and tracking systems [25]. But now I found myself in need of them.

This was the time and place of the first of many conflicts. As a researcher seeking to modify my body how could I be both a participant in systems like these-systems backed by what I saw as rationalist agendas threatening self-knowledge, intuition and reliance-and still champion a resistance against them? How could I inhabit and speak from what [12] refers to as the normalised position of a diet participant, and one of a resister?

Would I be taking these systems and their ideologies down from the inside? Maybe, I told myself, I'd get to that after I got my 6-pack, washboard abs. Then it would be down with the tyranny of rational reporting systems and selfsurveillance.

But first, I needed a truce with that inside me that I thought was working against my best interest. And it appeared that the best way for me to do that was to swallow my pride and call in a mediator. And so, like any well-meaning, wellconnected person of my age, means, and technological background would, I chose the Internet and my smartphone to help me do so. And, as it turned out, there were many apps for that.

\section{LOSING IT}

It was 22 months into my project, and I had exceeded my early goals only to find myself frustrated with stalled progress in newer, ever-more fantastic schemes of self-transformation. In the pursuit of pinpoint diagnosis, I lay still on a hard counter in a dark room breathing into a small device of bleeps and bloops as it tried to measure my basal metabolical rate. 1950. Should I be relieved at this number? How did I get here?

It began with a scale. I told it my age and my height, stepped on, and in reply it told me my weight and body composition: 5' 8, 174lbs and $24 \%$ fat. This was, for me, an uncomfortable conversation. I felt a stranger to this self.

A week later, I downloaded and started using Lose It!, a weight-loss and calorie tracking application for the smartphone and web. At the time, it had several features broadly representative of dominant calorie tracking and weight loss systems: the ability to track overall calories along with nutrients, budgeted according to reported weight and estimated metabolism; a large database of food items and the ability to scan packaged, bar-coded foods into that catalog; the ability to further extend that local database by creating new ingredients or saving food combinations as recipes. It also had two other features that I avoided, primarily around motiva- tion. One was a simple social network designed to promote encouragement between users and to route encouragement to and from Facebook \& Twitter, and the other was a sponsored motivation system of reminders, with badges (Figure 1) awarded to users at particular milestones, for example: the $10 \mathrm{lb}$ club; the regular user (every day for 2 weeks); the hardcore (26 weeks); the exercise buff, hound, and king; and, curiously, the Tea Time badge ("tea powered motivation brought to you by SPLENDA ESSENTIALS No Calorie Sweetener Products") for those who recorded enough cups of tea.
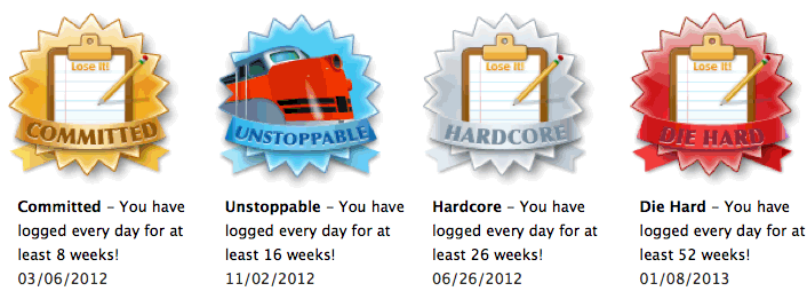

Figure 1. A sampling of the author's badges

I never used these features; they were antithetical to why I used the tool in the first place. I had no desire to share my progress with others, and motivation through competition or badges held little appeal. I learned to carve out a space between calls to upgrade for premium features and the emails announcing my new badges.

This work of finding spaces in a single app expanded into the formation of alliances, and then peace-keeping mandate within an ad hoc assembly. As the weeks and months went by, I auditioned, added, and managed many other mobile applications, physical tools, and fragments of knowledge. To name a few: calorie count, a nutritional database that I would consult to convert food into calorie and macronutrient values; Endomondo, my exercise tracking app that would report calories burned and detailed performance numbers from my bicycle rides; the Moves app and a FitBit device helped me keep track of places visited and steps taken; Gym Hero, PUSH, and Strong helped me track weightlifting workouts. Finally, a small scale, combined with measuring cups and spoons, provided predictability in the kitchen.

With this shifting team I set out to change my life, navigating a landscape of other tools and systems, online discussions, and professional advice. I consulted with trainers, physicians and nutritionists. I read internet forums of every kind. I scheduled physicals and full body density scans in cuttingedge machines (See figure 2).

Digital and paper journals helped me keep track of and reflect on my struggles and progress. Treating this an ethnographic encounter with my self, I began by taking frequent field-notes, recording and reflecting on goals, my progress towards them, and my developing relationship with these systems. I kept these notes in parallel with my expanding data recording, but those bars, curves, and data points were my reflections as well, my successes and trepidation encoded in their patterns and rhythms. The just-so upward slope of my 


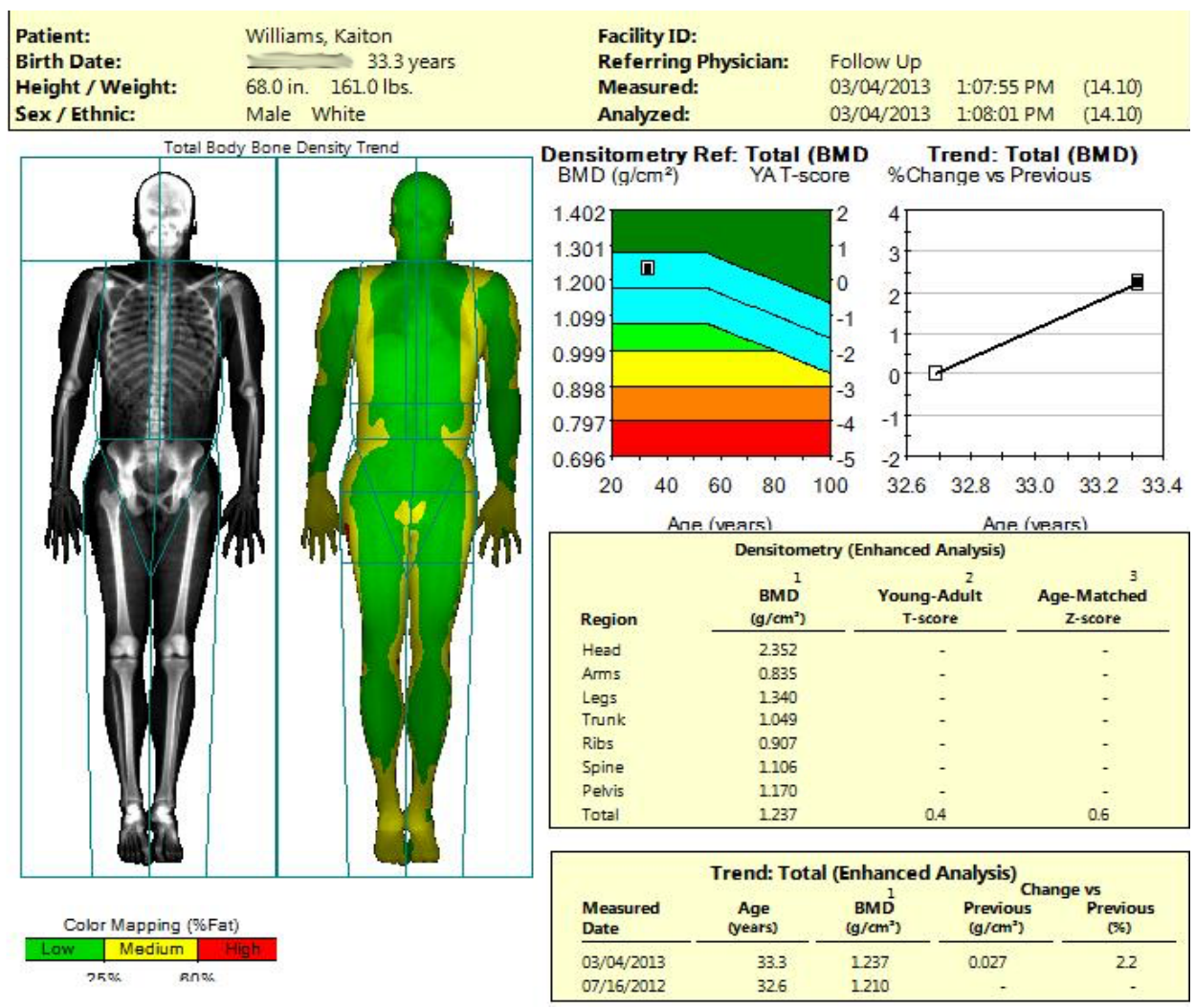

Figure 2. The results of a Dual-energy X-ray absorptiometry (DXA) scan

body-weight readings weeks after a holiday remains to me as evocative as a madeleine.

As I recorded I worried about how to explain and recount an experience steeped in numbers yet both fleeting and embodied. Should I try to separate my selves as recorder and recorded? In [20,36], the authors channel Bakhtin and Dewey to hold that this sort of aesthetic experience might be the paradigm for all experience, reflecting on Dewey's definition of experience as a double-barreled "unanalyzed totality" that "recognises in its primary integrity no division between act and material, subject and object"[20]. [33] describes this as a circularity, "where knowledge comes to be inscribed by being with the 'designing-being' of a tool, thus in turn modifying (designing) the being of the tool-user". I relaxed.

I drew inspiration from Neustaedter and Sengers' investigation of autobiographical design as a method that can provide detailed and experiential understanding of a design space [23]. My collection and curation of this menagerie of devices, applications, algorithms and APIs, and my fashioning and querying of reports and visualisations revealed itself as a form of design. I didn't write the software in my conglomerate but I do understand my role here as a designer, and this as a form of research through design $[10,37]$. I am designing myself, in collaboration with the systems I've cobbled together. In this we exist as anxious allies: body; device; data; cloud; others; algorithms; entrepreneurs.
This design is critical, reflective, ontological, and tinkeringwhat [33, 34] position as fundamental to being human wherein "we design...we deliberate, plan and scheme in ways which prefigure our actions and makings [and] in turn...are designed by our designing and by that which we have designed" [33]. This ontologically oriented understanding of design is "a philosophical discourse about the self-about what we can do and what we can be" necessarily "both reflective and political, looking backwards to the tradition that has formed us but also forwards to as-yet uncreated transformations of our lives together" [34]. This design is building as nurturing, not just constructing. And as we pervade the things we build, they in turn pervade us in a ways more fundamental than any single designer could consciously intend [33].

\section{LIVING AMONG THE NUMBERS}

Rearrange the icons on my home screen and my thumb is lost. It quivers, bent searchingly and confused. We had a system, it seemed to say. (fieldnote excerpt)

I enjoyed the everyday accounting. Entering in Lose It! the food I ate helped me reflect both on my food choices and on the events that surrounded them. The manual repetition of entries underwrote this: launch app, my thumb to the top corner of screen; "Add Food", type in food; choose the amount, arrange ingredients and meals in orders temporal and strategic.

40 taps and scrolls to enter a meal of broccoli, roasted chicken, and an arugula salad dressed simply. The result: 461 calories. An immediate question might be, could this 
be faster? And maybe in the beginning, I would have wanted that. I can even imagine someday an app will allow me to take a picture of my food and return structured data in a flash. But even the seemingly tedious has its attractions. Out for a meal, far away from measuring cups and scales, I gradually found play in reverse-engineering a dish back into composite ingredients and macronutrients.

The practice of recording is soothing and has its charms. I could reflect on the day's flow, wordlessly. I could watch the numbers accumulate and balance, as charts filled in and lines extended; a retelling of my day in a new narrative form. I found myself launching the app several times a day, often only to scroll laps through the day's huddled data.

Untended data pervades me as anxiously as an untended garden might, resulting in a "thinking as being with" [33]. The daily weeding, pruning and nurturing of data not only pays dividends over the long term but is rewarding and meditative in its own right. It is action with rewards at once past, present, and future. I take a quiet pleasure from lying in bed at the end of the day and looking up and confirming locations I've visited, all tracked in Moves. I rarely look back at the data analytically; rarely seek to recall where I was on a Monday night, 8 weeks before. But I'm happy to know that data's there, to feel its weight accumulating over time: the results of making paths in new cities, and retracing old ones in a familiar geography. They are all constellations in my private data mythology.

\section{An idiosyncratic self-knowledge}

Despite my success and its attendant numeric pleasures, I've yet to enjoy contemplating my self as a precarious balance of inputs and outputs: what I eat versus how much I exercise. I would have preferred to accomplish my self-transformation within broader measures, and I still long for that: to comprehend my body in longer and less granular scales-seasons instead of hours, calories banished altogether. A friend, at once svelte and blissfully ignorant, remarked in a conversation about my calorie goal that day: "I have no idea of calories / What amounts to 10 much less 1500." Even with my fitness goal surpassed, my body seemingly in the balance I sought, I could only reply: "That's actually beautiful."

Because it's as hard to imagine going back as it is to imagine going forward. I can't un-know the weight of things. As Dewey notes, "every experience both takes up something from those which have gone before and modifies in some way the quality of those which come after" [7, p27]. I had come to realise that an attention to ever smaller matters of concern could yield effective results, but at the same time I couldn't help but imagine myself bound to a future where I could scarcely ignore them. At least, not if I wanted to remain in my present condition. To know was now, in many ways, to be bound to manage and optimise. I was coming to view the insights my tools had begun to provide me, and my developing dependence and relationship with them, as unsteady.

But aren't we all wrapped up in similarly conflicted relationships-what Bourdieu referred to as "the Benthamite calculation of pleasures and pains, benefits and costs" [5]? Our modern life is as much defined by asceticism and denial as by gratification. To reach our goals we undertake broad changes in our lives: no meat; no dairy; no to the second drink; lock our WiFi router in a safe when we need to focus [28]. Why should this relationship be any different?

Why did I continue with a program that contradicted my ideals and left me in an unsteady position? For one, it worked, and worked quickly. The efficacy of the approach was difficult to deny. After the first 4 weeks I had lost $5.6 \mathrm{lbs}$ and I felt that I was arriving at a workable understanding of how what I ate affected my body. I felt healthy, and I was performing small experiments and getting valuable feedback: tuning the right amount of fibre, getting enough protein, monitoring my sugar intake. Still, I would tell myself that there were a number of other reasons that could have explained the changes to my body: I had a renewed awareness of my self and what I was eating; I was feeling less stressed now that I felt more in control; I was starting to use exact measures rather than estimating.

The numbers and their precision continued to have a mesmerising effect over me. Intellectually, I had serious concerns about the value of calories as the sole or even dominant basis for weight management-that all calories were equal-and though I tried to focus more on the ratios of nutrients or on the quality of my food, Lose It!'s calorie budget readout, with its scary red zone indication, remained a metaphysical hurdle difficult to clear. Even as my attachment to these tools has waned, I still view that threshold warily, finding soothing reward in almost always being several calories under it-safe in the green zone (see figure 3) - even though I both theoretically and practically know it to be imprecise and perhaps even inaccurate.

This was a surprising revelation. I knew intellectually that the numbers displayed in my app and used behind the scenes in its calculations were based on rough estimates or theories. And I knew how futile the notion of managing one's self to precise calorie budgets must be. I knew that, by describing our bodies as precise systems that can go out of sync based on small discrepancies, the health industry and app creators benefit by this positioning of their tools and systems as indispensable and necessary guides in our lives. Yet, months after that internal conversation, I continued to ask myself, "can our bodies really optimise down to a few calories?" while measuring out exactly 7 evenly-sized almonds for a quick snack.

I had begun to read non-weight-related features of my life through what [13] refers to as the "prism of weight loss." My days had been reshaped through those units of measure. My tools became my oracles, and I consulted them before planning meals or an evening out. Through them I acquired a fluency in the forms and verse of macronutrients.

Over the months I steadily made my life more calculable by streamlining my diet to in turn streamline how I input data into my tools. I prioritised certain foods and recipes, and avoided others to work best within the capabilities of the food database. I weighed my food or measured it by the fluid 
Figure 3. Calorie Thresholds: Day marked green are those with calories at least $1 \%$ below threshold; those marked red are more than $1 \%$ over the threshold; those in cream are within $+/-1 \%$ of the app's suggested goal

ounce. I groaned at foods that weren't in the database or occasionally at recipes that were too complicated to assess calories per serving once complete.

But still I found freedom in this calculation and control and room in its reduction. Regardless of whether the $\mathrm{I} / \mathrm{O}$, calories in vs. calories out, model was correct over the long term, I had found reassurance in its immediate results. Before I began this study I didn't know how many calories I was eating overall or how many calories were even in particular foods. I wasn't even aware of the mix of nutrients that I was eating. The apps provided me with expanded capabilities so that I was no longer eating "blindly." Pushed to spend more time reading nutritional labels and scanning food databases to enter into my tools, I realised how little I knew about what I had been eating.

I developed felt a strong sense of fidelity to my accumulated system; an ordained from Logos desire to keep the record true (read: often, precise). At the same time, I knew that I occasionally kept a false dialogue: over-estimating food items, or under-entering exercise. Why would I perform these small acts of rebellion even though they might ostensibly be against my self-interest? Why did I trust the system when it confirmed my "bad behaviour" but conspire to undermine its reports of when I was "good?" Even as I continued performing them, I wondered if these minor insurrections were how I came to terms with what seemed like an increasing rationality in my life.

Together, we-my system and I-had co-constructed a digital model of my self that I fully bought into and managed: managing myself, it seemed later, by proxy. Within this, I had found a practical way to consume much of the advice and research I would come across. With my model in hand, I felt a relationship between my data and my body, though I struggled to decide how much of that connection was real or imagined. When I didn't eat "enough" protein I felt weaker, and when I had too much sugar I felt fatter. These were delayed reactions - a re-reading of my body from the model. Had I sacrificed one balance for another, or balanced my model instead of my self? Did that final distinction even matter?

\section{Stepping Back}

Yesterday, after the gym, the scale showed $152.0 \mathrm{lbs}$ and $15 \%$ body fat. My weight has been hovering from 150 to 152 but with the fat level, it's safe to say this is the trimmest I've ever been. It's frightening to now reflect on what I carried around on my frame before. The task is now to keep keeping this weight off and to cement my progress with a good workout regimen. It's going to be a long fight but hopefully a happy one. (fieldnote excerpt)

As my study's initially projected run was coming to an end, my earlier fear of gazing too deeply at the messiness and viscera of being human was replaced with a gnawing worry about the feasibility about going it alone, even with my developing intuition. My reasons for continuing with this project were complicated: personal and professional, subject, steward, and researcher. Projects must end but what about the relationships I had developed within my alliance?

What would I do without my calorie tracker? How would I wean myself away even now that I had met some of goals that I had developed? I still think a lot about the transformation. I am now "in shape." I feel strong and healthy. This is a place that I had scarce considered before, but these numbers seem to hold as much fear as pleasure. Could I maintain this state without "outside" help?

Relying on my existing alliance was no sure path to reassurance either:

Back around 153, and it felt like it took too much doing. I'm not sure if I would have naturally made it back there or what the cause was. Was it a couple weeks eating [Lose It!'s] recommended 2000 calories? The flour of Denmark? The week in Seattle? There's a lot that happens in between the numbers.

[Two months later...] Confused with my weight. Moved too many variables and I don't know how to unwind it all (fieldnote excerpt)

And in the present, if I do cast these systems aside, would doing so really lead to any better engagement with my self? Granted, I am far better at mechanical feats of estimation and proportion, handily verifying my estimates when I enter them. And when I don't track, I survive, mostly without worry, because I've internalised and made habit of my food behaviours. The notion of a pure originary sealed-off self felt false.

As my project shifts from daily tracking and self-evaluations, and I continue to pursue personal goals, I realise that I can never truly divorce my personal and professional interests. I feel forever embroiled in an all-encompassing exploration of personal possibility and continuing improvement that pays no heed to disciplinary borders.

\section{CONTINUING IMPROVEMENT}

After a year, I had lost 24lbs, but my will to improve continued and expanded beyond weight loss. On one morning, after some reading on the Internet, news of Anterior Pelvic Tilt ${ }^{1}$ arrived in my life. I wrote later:

This is the weekend that I became aware, and seemingly a victim, of anterior pelvic tilt. The exercises to correct this have begun. Like many conditions, I doubt if I have it, though it would explain a great deal. And, as I've

\footnotetext{
${ }^{1} \mathrm{~A}$ posture defect
} 


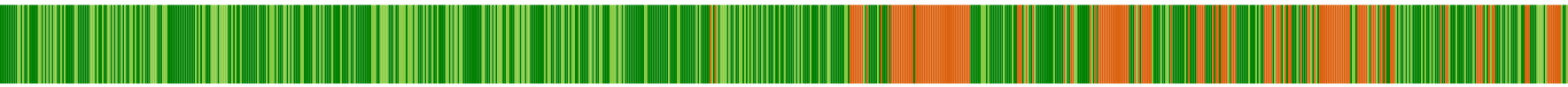

Figure 4. Tracked days: Both shades of green represent days that were tracked. Slices marked orange were days that I did not track. Days marked with a light green shade had their food entries edited retrospectively

\section{learned about other conditions, learning that you have something becomes an exhausting ride towards fixing it. (fieldnote excerpt)}

The universe of self-improvement was unfolding before me. Being healthy had become more than just avoiding obesity, sickness or early death. It had become what Rose refers to as the "optimization of one's corporeality;" a model of fitness that is "simultaneously corporeal and psychological" [27]. As I came to revel, with some conflict, in my new-found selfunderstanding and weight loss, I also began to wonder what I couldn't achieve given the right companion tools. I began weightlifting, tracking workouts and shifting my diet into performance mode; I experimented with tracking and optimising my sleep. Did coffee improve my focus? Wonder, track, and see. Track to peruse; then track to improve.

This new model of fitness and health embraces what Rose refers to as "overall well-being," inclusive of happiness, beauty, sexuality and more. What he concludes is that, spurred on by the privatisation of the health care industry and state efforts at health promotion, our personhood is increasingly being defined not just by ourselves, but by a complex of others; a complex that includes not just our immediate community but the application-creators, entrepreneurs and new media companies that are building on our desire to improve our selves. These collective decisions helped reshape how I perceived and contested my possibilities and limits. My algorithms and applications fit within the frame of this developing relationship with my self that was equally epistemological, attentive, and despotic [9].

By allowing insight into bodily processes, systems like mine increase our capacities and abilities: to critically assess "correct" functionality, to gauge inputs and outputs, and to help us regulate our processes or our models of them. At the same time though, as I felt, they encouraged our participation in networks of power that constrain us and might decrease our will or ability to exercise our capacities in the future [12]. That these networks of power are not just external (between us and the world) but also internal (between us and our selves) is what made a first-person evaluation so compelling yet simultaneously complex.

In my case, losing weight by controlling diet and exercise required an ability to re-construct my body as obedient and submissive through attention to small details and newly revealed units of measure. This is a "relentless surveillance" [3] wherein I partitioned my body into new dimensions. Yet, through this control and restriction, I became aware of exactly what I consumed and its effects, and came to realise the positive embodied and ontological effects that can accompany changing patterns in my life [13]. And the accomplishment of those goals, even if those goals might have been subliminally directed by, and entangled with, a complex of exter- nal sources-corporate or social-was still an enabling act of self-transformation that honed an ability to enhance capacities and to develop new skills. As my study progressed through its early phases, I had taken seriously Thoreau's admonition to avoid becoming "the tools of our tools" or putting too much, and too often, between ourselves and a direct connection to the world through our intuition [31]. At the same time, I had to admit that as my self-tracking practice developed, it helped me increase my awareness and intuitive sense of my self and my world.

That I had the advantage of a first person perspective is important to understand, but that I was party to an experience that transformed, over several months, the way in which I acted on, thought of, and was affected by the world through my body is equally important. Our bodies express our "double status as object and subject-as some-thing in the world and as a sensibility that experiences, feels, and acts in the world" [29]; yet the argument from that somaesthetic view is that the goal of objectivity and a nobler (in the enlightenment sense) version of humanity produces a one-sided focus on intellectual goals that marginalises studies of the body. But embodied considerations inform how we choose to form our existence, assess our quality of life, and make intellectual decisions. This is not just an anti-Cartesian position. Connecting with and attending to our bodies-even through these systems - might be a way to recuperate the kinds of aesthetic experience that can help us connect to others.

My experience has shown me that such a path is far from straightforward. Criticisms of these technologies show how they, or at least the imaginaries that give birth to them, promote and cement a division of mind and body, and work to establish a self-legible body that is always at risk yet best addressed through objective "information" [32]. At the same time, even as a prosthetic, that information system expanded my ability to make sense of the world and in doing so increased my sense of freedom (see [17] for a related example). Even the idea of the prosthetic felt limited, and the disjunctions between body and mind, tool and human, felt hard to maintain. Data, device, and person at times felt instead transduced and interwoven, and enabling new possibilities, capabilities, and connections to emerge [19]. Transduced and transformed, not only can I not cleave the entanglements between my self as subject and researcher, I am no longer the same person who began this study.

\section{COMMUNING: THE IMAGINED BOUNDARY OF OUR SELVES}

Taking Thoreau's notion of deliberate living seriously meant attending not only to the practical realities of my body and its immediate environment, but also to the social relations around me. For Thoreau, starting with the self was not a retreat but a strategy for re-engagement with the world. He 
wrote that "not till we are completely lost...not till we have lost the world, do we begin to find ourselves, and realise where we are and the infinite extent of our relations" [31].

My project changed my relationship to the world at large. In small ways, my conversations with those around me often centred on changes to my physical proportions, or changes to my diet. To others, my dietary choices and my measuring and data entry habits were, at best, curious, and, at their worst, alienating. Still, my admission of these quirks and personal challenges provided a common ground to discuss other struggles. They may not have been self-trackers or body-hackers but they all had goals they wanted to achieve.

As I presented ongoing work and told friends and family about my approach, responses were varied. Two responses stood out. I was either pitied: seen as someone crippled through an embrace of technology, bound by a system of measures and restraints. Or I was envied, my control of my diet and exercise taken as signs of a far reaching mastery of my larger life (no such power exists).

For those with whom I found similar ground, we were connected not because we used the same suite of tools, but because of a shared commitment to a subjunctive understanding of our systems. This was a view of the tools at our disposal as a range of approaches that provided craggy but passable conduits to an old self, a new self, or even a better grasp of a current self. Focusing on my personal, experiential knowledge provided a starting point for those conversations.

Thoreau's pursuit of self-knowledge had become a vehicle for self confrontation and a vantage point from which to confront his world with fresh perspective. His deliberate stripping down of his life and activities was done in order to recreate a more empathetic one, and he built to political action through this alternating retreat from and engagement with society. His concern was the development of a capacity to improve ourselves and our world. Our role as citizens to engage a wider culture can begin from movements both big, and in my case, small. I believe a cycling "retreat" into first-person studies is a similar and valid methodology for engagement with particular communities, one that fits within the frame and support demonstrated by third-person and structural approaches such as $[11,25,6]$.

My evolving relationship with my self and system has required me to be more critical of how I imagine my role. Is it as a critic and "defender"? Is it as a willing (and perhaps pitied) general participant? Is it as someone attempting a fused role somewhere between? As critics, if we decide to defend users against technology and social formations that we see as bad, where do we position ourselves? Are we part of the laity? Or are we standing apart, too savvy to be caught in the same traps? Does our writing, strategies, and commitments reflect that we too are in liminal positions? In [30], Taylor calls for us to view technology and its design as a "means of participating in unfolding ways of knowing, being and doing" rather than standing back here reporting on others out there. Might deeply personal accounts help us focus on what he refers to as the mutuality of our "unfolding enactments of ordering, classifying, producing and ultimately designing technology"?

When I began my project, I knew nothing of the Quantified Self (QS), a community of users and makers of self-tracking tools ${ }^{2}$ perhaps best known through its stated commitment to "self-knowledge through numbers." And yet, 2 years later, with only slightly more of a clue, I found myself giving a talk and running a workshop at an annual QS conference. In the years since I began this study, popular conversation and critical discourse on the QS movement in particular, and on the wider practices of self-tracking in general, have increased, while its related devices and approaches have entered the mainstream. It's now commonplace to meet people equipped with some form of automated personal tracking clipped to waist or wrist.

An outsider view of this community might likely mirror the view that others sometimes take of me, and that I had initially taken of it: as narcissistic or self-indulgent; as trapped in a corporate designer's ideology; or as a member of a cabal determined to increase rationalisation in our lives and to make data of our bodies. It was perhaps too easy for me as a critic to see my charge as rescuing the naive from the great evil of such an imagined neo-liberalist scheme of big data, surveillance, and individualising institutions.

Of course, there are reasons to decry and worry about such an encroaching future of personal panopticons, and individuals alienated from supporting institutions that are divesting themselves from social responsibility for issues of health. But instead in QS I found positive possibilities among selves and other-where other might be a device, a database, or a community of people. And it helped me see the boundaries that I initially considered between myself and my devices, and between myself and others, as imaginary and limiting. I have now begun to rethink tracking practice as something more akin to a cyborg communion: with devices, others, and self. Does it stretch the bounds of the scholarly tent too far to think of us as bridged by data, or as connected by a joint recognition and quest for the sublime?

I don't mean to paint the pursuit of personal informatics as a religious one, although I'm sure it has its zealots. And I don't maintain that all or even many members of the Quantified Self community would agree with my characterisation. In fact, my presence and that of other critics who wished to inject more reflection on QS's effect on the wider public provoked some understandably negative reactions. After all, why should individuals in a community have to worry about the consequences that might spiral indirectly from their individual practice?

I've wondered the same. Friends and family have now followed my lead, tracking activity and intake. They've seen great results but I worry that I've caught them in a subjunctive net that I can give little advice on how to fully escape.

What I found QS to be was markedly different from the majority if the popular media and critical academic discourse about the movement. Their relationship with data was pro-

\footnotetext{
${ }^{2} \mathrm{http}: / / q u a n t i f i e d s e l f . c o m / a b o u t /$
} 
foundly different from what I had come to expect, yet profoundly similar to how I felt. Our questions were similar: what data is important? Who gets to say so? What does it mean for me? In a breakout session I led-provocatively titled Can Data Make Us More Human?-I asked what values and considerations were important to the participants. The responses were instructive:

ease of use, transformation, openness, freedom, honesty and directness, reflexivity, presence, constancy, comfort, anchor, exchange, to find better questions, to create my own narrative, how do I want to live?

objectivity, to make order, tangibility, discipline, selfcontrol, autonomy,

diversity, transparency, accountability, value-free, judgement-free, guilt-free,

living better in the moment,

diversity, fragility, empathy

Nafus and Sherman [22] argue that QS practices are actually "soft resistance" to institutional models of producing and living with data: "a readiness to evolve what constitutes meaning as it unfolds." With this form of resistance, they find that QS participants "work to dismantle the categories that make traditional aggregations appear authoritative". Using systems like Lose It!, that were built with seemingly helpful badges, gamification, and databases flush with particular kinds of food, helped me understand firsthand those struggles of being enrolled in, while simultaneously wrestling with, embedded ideologies of how best to monitor and manage one's health and person. The community members I met were in a similar struggle, also attempting to work around systems largely designed to meet purposes with which they did not completely identify. This was not a site where self-authority was being ceded nor one where a joint search for an objective, external locus of meaning making was being launched. It was a place where data and devices were being used to reflect on what may or may not be happening inside our bodies, and to insist on the "idiosyncrasy of individual bodies and psyches" [22].

This difference echoes Ingold's [15] distinction between wayfaring and transport. For Ingold, transport is distinguished from wayfaring not through the use of devices (mechanical means) but by what he refers to as the "dissolution of the intimate bond that in wayfaring couples locomotion and perception." The transported traveller is a passenger, one who "does not himself move but is rather moved from place to place," while the wayfarer goes along and threads a way through the world rather than routing across the surface from point to point. This leads to a fundamental difference in the integration of knowledge, where wayfarers "grow into knowledge of the world about them" while in transport, knowledge is upwardly integrated.

The QS discussions and presentations that I've been privy to are less about reading results and more about following a trail where participants, following Ingold, know as they go: sharing an always-bound trifecta of what they did, how they did it, and what they learned. This a way of knowing which reflects what he refers to as "a path of movement through the world" rather than a reliance on rigid distinctions between the mechanics of capture and the formation of knowledge. The alternative - "the possibility of pure transport"-is an illusion: we cannot escape the methods we use to frame and capture our data, nor can we as self-trackers "ever be quite the same on arrival at a place as when [we] set out." My earlier understanding of the community and my own developing practice as a collection of numbers missed this rich ontological designing, and saw transport in attempts at wayfaring.

\section{CONCLUSION}

I had a single, simple goal when I began this project: to lose some weight. To achieve this goal, I brought a range of systems within the limits of my self, and we made more goals in collaboration; mutually designed as we were designing. At various points in this journey I felt lost: out of touch with my numbers, my narrative, and even my collective. But I found that losing myself was essential to continuing onward.

The use of my self as subject was an important vehicle for getting close to the difficulty of mapping and communicating such an experience: a model of knowledge acquisition equally epistemological and existential. Knowing logically what to expect during this project did little to prepare me for the daily mixture of sadness, elation, and fear that I experienced. I knew that numbers, and the intimate devices that deliver them, have a powerful force on us, but to experience that somehow-embodied tug was important. And that I did this with personal and professional consequences at stake is a productive complication that I am still unraveling. The last years have been more than an academic research opportunity. They also represented an important effort and transformational experience linked to my own ideas of self-worth.

My particular choices helped me reveal and begin to come to terms with the nuances of an internally conflicted position. Long-term usage coupled with an existing personal need modulated my position on health and fitness technologies, confirming some of my criticisms but substantially reframing my prior estimations. While I remain cautious of the approaches of many of these systems, I learned that my conflicted position need not be hypocritical, and reflects the joys and capabilities that can be found in reduction, and the freedom to be found in control. I had been wary of the attractions of these technologies, and found that confirmed in my connection to them; I was not in a comfortable space of ironic distance. Many of the theoretical issues that concerned me prior to my project, such as the reductionism inherent in a calorie-based point of view and the limitations of the modelled "truths" that these technologies are predicated on, remained with me throughout, but were experienced anew.

My intent has not been to present a thorough record of this journey but to demonstrate a struggle to make sense of it. What I tried to provide was a form of extensive, genuine usage that responds to what [23] refers to as "detailed, nuanced, and experiential understanding of a design space." But this is a design space in which I exist as subject, object, and verb-a perspective that, at once privileged and problematic, elastically collapses subject and researcher. 
Through the essay I tried to make two main contributions (topical, methodological), but without distinct separations of section which I feared would too easily mirror these binaries against which the essay also labours. Given the underlying approach (autoethnography, research through an ontological design), only discussing the method without showing it in action would likely not make a compelling argument, nor would deploying it without also arguing significantly for its validity. As such, this essay leaves much unresolved. In this though, it is faithful to my underlying experience, and responsive to the calls to action in [20] and [30].

I hope that writing about this project in a first person, autobiographical voice helps to fulfil a commitment to support a "fuller range and richness of lived experiences" [4], wherein we draw on aesthetic principles and techniques $[1,21,35]$ to achieve that goal. As a method for both understanding others and the self, I believe this voice marries well with a desire to deeply describe and engage with those moral, political, emotional and ineffable experiences in our work. That said, the value for me has not been in whether I could reveal different things than a more traditional third-person approach might, but whether I might be allowed a look at the same things in a different way $[3,26]$.

I don't assume though that my experiences will be the same as others. I hope to read other accounts that will be markedly different. This has been an unabashedly person-centred attempt to present a perspective on these systems and communities that is not common within HCI, and in doing so to hopefully expand its tent. I tried to present as much of an inner view possible but that view is inescapably complex, obscured, and contradictory. Instead of attempting to transform an idiosyncratically personal account into a directly generalizable one, I opted to draw out and demonstrate a connection between a personal and embodied foundation, and a broader politically and socially engaged position — one that should not require us to gloss over or reduce our individual distinctions.

It may be that to live with these technologies is to be necessarily-not just until the version next-in alliances marked by these capabilities and productive contradictions, and by the frequent negotiating and renegotiating of perspectives and boundaries. In this, they are perhaps but another set of relationships among many others in our lives; a collection of others that have always been expanding the limits of our selves.

\section{ACKNOWLEDGMENTS}

This work was funded through the Intel Science \& Technology Centre for Social Computing, and NSF Grant IIS1217685. I'm particularly grateful for the thoughtful feedback and support of Phoebe Sengers over the years of the study, and to the helpful comments, criticisms, and suggestions of the anonymous reviewers.

\section{REFERENCES}

1. Bardzell, J. Interaction criticism and aesthetics. In Proceedings of the SIGCHI Conference on Human Factors in Computing Systems, CHI '09, ACM (New York, NY, USA, 2009), 2357-2366.
2. Bardzell, J. HCI and the Essay: Taking on "Layers and Layers" of Meaning. In CHI 2010 Workshop on Critical Dialogue (Sept. 2010).

3. Bartky, S. L. Toward a Phenomenology of Feminist Consciousness. Social Theory and Practice 3, 4 (1975), 425-439.

4. Boehner, K., Sengers, P., and Warner, S. Interfaces with the ineffable: Meeting aesthetic experience on its own terms. ACM Trans. Comput.-Hum. Interact. 15, 3 (Dec. 2008), 12:1-12:29.

5. Bourdieu, P. Distinction: a social critique of the judgement of taste. Harvard University Press, Cambridge, Mass., 1984.

6. Brynjarsdottir, H., Håkansson, M., Pierce, J., Baumer, E., DiSalvo, C., and Sengers, P. Sustainably unpersuaded: How persuasion narrows our vision of sustainability. In Proceedings of the SIGCHI Conference on Human Factors in Computing Systems, CHI '12, ACM (New York, NY, USA, 2012), 947-956.

7. Dewey, J. Experience and education. The Macmillan company, New York, 1938.

8. Efimova, L. Weblog as a personal thinking space. In Proceedings of the 20th ACM Conference on Hypertext and Hypermedia, HT '09, ACM (New York, NY, USA, 2009), 289-298.

9. Foucault, M., Martin, L. H., Gutman, H., and Hutton, P. H. Technologies of the self: a seminar with Michel Foucault. University of Massachusetts Press, Amherst, 1988.

10. Gaver, W. What should we expect from research through design? In Proceedings of the SIGCHI Conference on Human Factors in Computing Systems, CHI '12, ACM (New York, NY, USA, 2012), 937-946.

11. Grimes, A., Tan, D., and Morris, D. Toward technologies that support family reflections on health. In Proceedings of the ACM 2009 International Conference on Supporting Group Work, GROUP '09, ACM (New York, NY, USA, 2009), 311-320.

12. Heyes, C. J. Foucault goes to weight watchers. Hypatia 21, 2 (2006), 126-149.

13. Heyes, C. J. Self transformations: Foucault, ethics, and normalized bodies. Oxford University Press, Oxford, 2007.

14. Höök, K. Transferring qualities from horseback riding to design. In Proceedings of the 6th Nordic Conference on Human-Computer Interaction: Extending Boundaries, NordiCHI '10, ACM (New York, NY, USA, 2010), 226-235.

15. Ingold, T. Lines: a brief history. Routledge, 2007, ch. Up, across and along, 72-103.

16. Latour, B. We have never been modern. Harvard University Press, Cambridge, MA, 1993. 
17. Leshed, G., Velden, T., Rieger, O., Kot, B., and Sengers, P. In-car gps navigation: Engagement with and disengagement from the environment. In Proceedings of the SIGCHI Conference on Human Factors in Computing Systems, CHI '08, ACM (New York, NY, USA, 2008), 1675-1684.

18. Ljungblad, S. Passive photography from a creative perspective: "if $i$ would just shoot the same thing for seven days, it's like... what's the point?". In Proceedings of the SIGCHI Conference on Human Factors in Computing Systems, CHI '09, ACM (New York, NY, USA, 2009), 829-838.

19. Mackenzie, A. Transductions: bodies and machines at speed. Technologies. Continuum, London, 2006.

20. McCarthy, J., and Wright, P. Technology as experience. MIT Press, Cambridge, Mass., 2004.

21. McCarthy, J., and Wright, P. Putting 'felt-life' at the centre of human-computer interaction (hci). Cognition, Technology \& Work 7, 4 (2005), 262-271.

22. Nafus, D., and Sherman, J. Big data, big questions this one does not go up to 11: The quantified self movement as an alternative big data practice. International Journal of Communication 8, 0 (2014).

23. Neustaedter, C., and Sengers, P. Autobiographical design in hci research: Designing and learning through use-it-yourself. In Proceedings of the Designing Interactive Systems Conference, DIS '12, ACM (New York, NY, USA, 2012), 514-523.

24. Perec, G. Species of spaces and other pieces. Penguin Books, London, England; New York, N.Y., USA, 1997.

25. Purpura, S., Schwanda, V., Williams, K., Stubler, W., and Sengers, P. Fit4life: The design of a persuasive technology promoting healthy behavior and ideal weight. In Proceedings of the SIGCHI Conference on Human Factors in Computing Systems, CHI '11, ACM (New York, NY, USA, 2011), 423-432.

26. Reed-Danahay, D. Auto/ethnography: rewriting the self and the social. Berg, Oxford, 1997.

27. Rose, N. The politics of life itself. Theory, Culture \& Society 18, 6 (2001), 1-30.

28. Schüll, N. D. The folly of technological solutionism: An interview with evgeny morozov. http://www.publicbooks.org/interviews/the-folly-oftechnological-solutionism-an-interview-with-evgenymorozov, September 2013.

29. Shusterman, R. Thinking through the body, educating for the humanities: A plea for somaesthetics. The journal of aesthetic education 40, 1 (2006), 1-21.

30. Taylor, A. S. Out there. In Proceedings of the SIGCHI Conference on Human Factors in Computing Systems, CHI '11, ACM (New York, NY, USA, 2011), 685-694.
31. Thoreau, H. D. Walden, Or, Life in the Woods. Penn State Electronic Classics Series. The Pennsylvania State University, 2006.

32. Viseu, A., and Suchman, L. Wearable Augmentations: Imaginaries of the Informed Body. In Technologized Images, Technologized Bodies, J. Edwards, P. Harvey, and P. Wade, Eds. Berghahn, 2010.

33. Willis, A.-M. Ontological designing: Laying the ground. In Design Philosophy Papers Collection Three. Ravensbourne (Qld, Aust): Team D/E/S Publications, 2007, 80-98.

34. Winograd, T., and Flores, F. Understanding computers and cognition: a new foundation for design. Ablex Pub. Corp., Norwood, N.J., 1986.

35. Wright, P., and McCarthy, J. The value of the novel in designing for experience. Future Interaction Design. Springer (2005), 9-30.

36. Wright, P., and McCarthy, J. Empathy and experience in hci. In Proceedings of the SIGCHI Conference on Human Factors in Computing Systems, CHI '08, ACM (New York, NY, USA, 2008), 637-646.

37. Zimmerman, J., Forlizzi, J., and Evenson, S. Research through design as a method for interaction design research in hci. In Proceedings of the SIGCHI Conference on Human Factors in Computing Systems, CHI '07, ACM (New York, NY, USA, 2007), 493-502. 